\title{
ANALISIS PERBEDAAN PENGARUH KEPUASAN TERHADAP KEPERCAYAAN DAN LOYALITAS PASIEN
}

\author{
Raditya Sukmana ${ }^{1)}$ \\ Ririn Tri Ratnasari' \\ ${ }^{1)}$ Fakultas Ekonomi dan Bisnis, Universitas Airlangga \\ e-mail: momyadit@gmail.com \\ ${ }^{2)}$ Fakultas Ekonomi dan Bisnis, Universitas Airlangga \\ e-mail: ri.ratnasari@gmail.com
}

\begin{abstract}
This study aims to determine that the effect on patient satisfaction and patient trust in RSI and RKZ. Effect on patient satisfaction and loyalty in RKZ and RSI, and patients' trust effect on patient loyalty in RSI and RKZ. The approach will be used for this research is a quantitative research approach. The population in this study were patients who take medication and inpatient treatment at the Islamic Hospital and in RKZ Vincent's Hospital for more than 1 (one) week in the period June to August. The number of total sample of 100 patients, divided into two, namely 50 Islamic Hospital patients and 50 patients in RKZ Vincent Hospital. The way sampling is purposive sampling. The analysis technique used in this research is path analysis. These results indicate that the effect on patient satisfaction and patient trust in RSI and RKZ. Effect on patient satisfaction and loyalty in RKZ and RSI, and patients' trust effect on patient loyalty in RSI and RKZ. Suggestions for the management of Islamic Hospital, should have to pay attention to the complaints of patients and the need to respond quickly to patient complaints regarding jenguk limited hours and take turns. For further research, research must be done by inserting a variable level of knowledge of religion and gender as a moderator variable.
\end{abstract}

Keywords: satisfaction, trust, loyalty

\section{PENDAHULUAN}

Aktivitas pemasaran tidak hanya menekankan proses melakukan transaksi saja. Setelah adanya transaksi antara penjual dan pembeli, pihak pemasar (penjual) harus tetap memiliki suatu hubungan dengan pelanggannya. Para praktisi dan akademisi mulai menyadari pentingnya hubungan yang dilakukan antara pemasar dan pelanggan. Hal ini menjadikan dasar bagi konsep pemasaran relasional (relationship marketing) untuk berkembang (Gronroos, 1997).

Perhatian terhadap pemasaran relasional juga semakin meningkat setelah adanya penelitian yang mengemukakan bahwa lebih baik mempertahankan pelanggan lama daripada berusaha untuk memperoleh pelanggan baru (Abratt dan Russel, 1999). Hal ini disebabkan oleh, antara lain, biaya untuk memperoleh atau menarik pelanggan baru lebih tinggi daripada biaya yang digunakan untuk tetap memelihara dan menjaga hubungan dengan pelanggan (Emnew dan Binks, 1996).

Morgan dan Hunt (1994) menyatakan bahwa dalam membangun pemasaran relasional harus diperhatikan yaitu kepercayaan (trust) dari semua pihak yang terlibat 
dalam aktivitas tersebut. Agar pemasaran relasional yang dilakukan oleh perusahaan dapat berjalan dengan baik perlu diperhatikan pula pemahaman pemasaran relasional dari sudut pandang pelanggan. Bagi pelanggan, untuk dapat terlibat dalam pemasaran relasional juga dibutuhkan adanya kepercayaan dan komitmen. Oleh karena itu, pemahaman pemasaran relasional dari sudut pandang pelanggan adalah timbulnya kepercayaan pelanggan.

Sebagaimana dikutip dari Chaplin dan Terninko (2000) bahwa perusahaan seharusnya benar-benar mendengarkan pelanggan mereka dengan menyaring apa yang dikatakan mereka, sehingga dapat melakukan perbaikan proses layanan yang efektif atas kinerja layanan, dimana pada saat mendatang, perusahaan layanan dapat melanjutkan proses investasi dengan mengadaptasi perubahan lingkungan yang sangat cepat, sehingga mampu bertahan dalam persaingan, apalagi saat ini, sedang hangatnya isu spiritual marketing.

Sebenarnya, spiritual marketing ini dapat dilaksanakan dengan optimal jika dalam segala aktivitas sehari-hari seorang muslim menempatkan Tuhan sebagai stakeholder utama. Inilah perbedaaan pokok antara pemasaran biasa/konvensional dan spiritual marketing. Seorang Muslim menempatkan Tuhan sebagai satu-satunya pemilik kepentingan (the ultimate stakeholder). Akuntabilitas dan responsibilitas diterjemahkan sebagai pertanggungjawaban di Padang Masyar (yaumul hisab) kelak, yang merupakan pengadilan abadi terhadap sepak-terjang manusia (termasuk para pelaku bisnis), baik yang tersurat maupun yang tersirat. Allah Swt. berfirman, "Apakah manusia mengira bahwa ia akan dibiarkan begitu saja (tanpa pertanggungjawaban)?” (QS Al-Qiyamah: 36).

Dalam kitab suci Al-Qur'an (Al-Baqarah: 275), terdapat sepenggal ayat yang berbunyi,"Allah telah menghalalkan jual-beli”. Agama membolehkan marketing. Dengan demikian konsep marketing (pemasaran) selalu disertai dengan istilah solusi dan kepuasan. Nabi Muhammad saw telah mengajarkan pada umatnya untuk selalu berbuat baik kepada orang lain. Inilah sebenarnya dasar dari pelayanan yang optimal (service execellent). Sabda Nabi, "Semoga Allah Swt memberikan rahmat-Nya kepada orangorang yang murah hati/sopan pada saat dia menjual, membeli, atau saat dia menuntut haknya". Allah Swt juga telah menginstruksikan untuk senantiasa berbuat baik kepada orang lain. Firman Allah Swt di antaranya terdapat dalam QS. Al-Hijr: 88, yang artinya: "Dan berendah dirilah kamu pada orang-orang yang beriman", juga dalam firman-Nya pada QS. Ali 'Imran: 159, yang artinya: "Dan sekiranya kamu bersikap keras lagi berbuat kasar, tentulah mereka menjauhkan diri dari sekeliling kamu".

Penelitian ini sangat perlu dilakukan karena dapat diketahui seberapa besar pengaruh kepuasan pasien terhadap loyalitas pasien baik secara langsung maupun tidak langsung yaitu melalui kepercayaan pasien. Penelitian ini membuktikan apakah pelayanan dari rumah sakit yang berbasis Islam yaitu Rumah Sakit Islam Jemursari di Surabaya yang seharusnya menjadikan Al-Qur'an dan Al-Hadist menjadi acuan, berbeda dengan pelayanan yang diberikan oleh rumah sakit Kristen yaitu rumah sakit RKZ Vincentius A Paulo di Surabaya. Dengan demikian, diharapkan dari penelitian ini akan diperoleh temuan-temuan yang menarik.

\section{KAJIAN TEORI}

Kepercayaan (trust) menurut Morgan dan Hunt (1994) adalah ketika seseorang memberikan kepercayaan pada pihak lain yang dapat dipercaya dan memiliki integritas. Hal ini juga sejalan dengan pendapat Moorman, Deshpande, dan Zaltman (1993) bahwa kepercayaan adalah keinginan untuk mempercayakan sesuatu kepada orang lain yang dapat dipercaya. 
Garbarino dan Johnson (1999) juga menambahkan bahwa pelanggan memandang kepercayaan merupakan faktor yang menentukan hubungan di masa depan. Menurut Ullrich (1994) hal ini dikarenakan kemampuan perusahaan untuk dapat menciptakan dan mengembangkan suatu hubungan yang bersifat jangka panjang dengan pelanggan sangat berkaitan dengan kemampuan dan motivasi dari masing-masing individu. Lebih jauh lagi, Sheth dan Parvatiyar (1995); Keegan, Moriarty, \& Duncan, (1995); dan Gummesson, (2000) menyatakan bahwa dengan adanya pemasaran relasional dapat mendorong timbulnya loyalitas pelanggan. Di sisi lain, loyalitas juga akan meningkat sejalan dengan meningkatnya kepercayaan (Silverhart, 2004).

Namun, agar pemasaran relasional dapat diimplementasikan, maka pelanggan harus termotivasi untuk melakukan suatu hubungan (relationship) (Beatty, 1996). Salah satu faktor yang menyebabkan pelanggan terlibat dalam suatu hubungan dengan perusahaan adalah kepuasan pelanggan. Pengertian kepuasan pelanggan menurut Oliver (1997) adalah "The consumer's fullfilment response. It is a judgement that a product or service feature, or the product or service itself, provided (or providing) a pleasurable level of consumption related to fullfilment, including levels of under or over fullfilment". Kepuasan adalah tanggapan pelanggan atas adanya pemenuhan yang merupakan sebuah penilaian bahwa karakteristik sebuah barang atau jasa mampu menyediakan pemenuhan yang menyenangkan, meliputi tingkat di bawah pemenuhan atau diatas pemenuhan.

Kepuasan pelanggan (customer satisfaction) merupakan perasaan (feeling) pelanggan dalam menanggapi dan mengevaluasi pengalaman setelah menggunakan suatu produk (Woodruff, 1997), yang dapat memenuhi bahkan melebihi kebutuhan, keinginan, dan harapan mereka (Band, 1991).

Abratt dan Russel (1999) menyatakan dengan diterapkannya pemasaran relasional, perusahaan akan memberi perhatian lebih banyak kepada pelanggan, sehingga pelanggan merasa diperlakukan berbeda. Perhatian perusahaan terhadap pelanggan dapat mendorong kepuasan. Jika pelanggan puas, maka akan timbul loyalitas. Keegan, Moriarty, dan Duncan (1995) menambahkan pemasaran relasional merupakan usaha yang dilakukan oleh perusahaan dengan cara membangun hubungan kerjasama dengan pelanggan. Rutledge dan Nascimento (1996) menambahkan bahwa kepuasan pelanggan atas layanan kesehatan makin banyak disorot, karena menjadi isu penting, di mana kepuasan pelanggan (pelanggan) akan memungkinkan untuk mempengaruhi apakah seseorang akan mencari kembali perusahaan layanan kesehatan dan membina hubungan jangka panjang dengannya.

Namun, Peppers dan Rogers (2004) mengemukakan bahwa pelanggan yang puas tidak selalu berarti (menjamin) bahwa pelanggan itu akan loyal. Reicheld (1993) yang mengutip pendapat Storbacka, Strandvick, dan Gronroos menambahkan bahwa dari hasil penelitian yang telah dilakukan, $65 \%$ - 85\% pelanggan yang meninggalkan perusahaan sebenarnya merasa puas. Reicheld (1993) menyatakan bahwa pelanggan yang tidak puas dapat tetap loyal, karena adanya switching cost yang tinggi. Peppers dan Rogers (2004) memerinci swithing cost terdiri dari biaya, waktu, usaha, atau uang. Hal ini membuktikan bahwa pelanggan yang loyal belum tentu puas, begitu pula pelanggan yang puas belum tentu loyal. Hal ini menunjukkan bahwa untuk mencapai loyalitas, terdapat variabel lain yang berperan sebagai perantara dari kepuasan pelanggan. Dengan demikian, kepuasan pelanggan secara tidak langsung akan mempengaruhi loyalitas pelanggan.

Sejalan dengan uraian di atas, penelitian yang telah dilakukan oleh Bloemer dan Odekerken-Schroder (2002) menemukan bahwa kepercayaan yang dibangun oleh 
pelanggan merupakan mediator atau perantara dari hubungan antara kepuasan dengan loyalitas pelanggan. Penelitian ini menunjukkan bahwa kepuasan secara positif menguatkan kepercayaan pelanggan dan mengarahkan mereka hingga akhirnya mampu meningkatkan loyalitas pelanggan dalam bentuk word of mouth, niat membeli (purchase intention), dan ketidakpekaan terhadap harga (price insensitivity).

Morgan dan Hunt (1994) mengatakan bahwa kunci utama dalam membangun pemasaran relasional, yaitu kepercayaan, berperan sebagai dua variabel mediasi atau sering disebut sebagai The Key Mediating Variable Model. Bloemer dan OdekerkenSchroeder (2002) mengatakan bahwa variabel mediasi ini menghubungkan antara kepuasan pelanggan dan loyalitas pelanggan. Di sisi lain, sebagaimana Hennig-Thurau dan Klee (1997) yang telah melakukan penelitian dengan melihat hubungan antara kepuasan pelanggan dengan loyalitas pelanggan, pemasaran relasional yaitu kepercayaan memiliki arti sangat penting, yang menunjukkan bahwa antara kepuasan dan loyalitas juga terdapat pemasaran relasional. Meskipun demikian, Aaker (1991), Oliver (1997) dalam penelitiannya menemukan adanya hubungan yang kuat antara kepuasan dengan loyalitas pelanggan.

Sebenarnya, jauh sebelum para ahli pemasaran konvensional berbicara, ribuan tahun lampau, maka Allah Swt telah memberikan tuntunan kepada umat-Nya, agar ketika memproduksi barang atau memberikan layanan kepada saudaranya (pelanggannya), maka sudah seharusnya memberikan yang baik. Ketika seorang pemasar menyebut nama Tuhan-nya Yang Maha Pengasih lagi Maha Penyanyang ketika ia memulai sesuatu, berarti ia tidak mengharapkan apapun, kecuali keberkahan dan keridhaan dari Tuhan-nya (spiritual goal). Kalaupun ada tujuan lainnya-emotional goal atau rational goal- maka pemasar tidak akan menempatkannya lebih tinggi daripada spiritual goal. Hal inilah yang menjadi motivasi mendasar dari seorang Muslim dalam melakukan apapun, termasuk didalamnya adalah melakukan usaha perdagangan dan pemasaran yang berbeda dengan motivasi seorang yang melepaskan ajaran Islam dari kehidupannya, di mana mereka hanya berorientasi pada materi/laba.

Bisnis yang berkah dapat diawali dengan sedikit untung banyak laku. Setiap pihak tentunya ingin menikmati keuntungan, baik produsen maupun pelanggan. Itu sudah sunatullah. Sedangkan menurut Islam, bisnis yang paling menguntungkan adalah bisnis yang membuat sebanyak-banyaknya orang merasa diuntungkan. Bisnis syariah seperti perbankan Islam, adalah bisnis yang mengandung keadilan dan prinsip-prinsip etika yang tinggi. Allah Swt. dengan tegas mengatakan bahwa dalam bisnis syariah haram hukumnya menzalimi satu sama lain. Hal ini mengacu pada Firman Allah Swt: “... Kamu tidak (boleh) menzalimi dan tidak pula dizalimi ..."Al-Baqarah [2]; 279; serta Firman Allah Swt : “... Dan Allah tidak menyukai mereka yang berbuat zalim ...” “... Dan Allah tidak meyukai mereka yang berbuat kerusakan ...".

Saat menikah, ternyata Nabi Muhammad SAW (sebelum menjadi Nabi dan Rasulullah) sanggup menyerahkan puluhan unta muda sebagai mas kawin. Jika dirupiahkan untuk konteks sekarang, maka jumlah mas kawinnya sekitar satu miliar rupiah. Peristiwa ini merupakan hal yang luar biasa. Padahal, pada saat merintis usaha, ia tidak memiliki modal sepeser pun. Nabi Muhammad SAW hanya mengandalkan kredibilitas. Kredibilitas ini berasal dari jujur terpercaya, cakap memuaskan, kreatif inovatif. Selanjutnya, sesuatu itu pantas dikatakan untung, seandainya semakin tumbuh bisnis yang sedang dijalankan, semakin berkembang pula kualitas kepribadian seseorang. Maksudnya, baik ilmu maupun pengalaman seseorang kian bertambah. Hal ini sesuai dengan Firman Allah Swt yang 
artinya "Barang siapa yang hari ini lebih baik daripada hari kemarin, maka ia merupakan orang yang beruntung" Jika sama saja, maka mereka adalah orang yang merugi. Jika lebih buruk, maka mereka adalah orang yang celaka (Gym dan Santoso, 2006).

Islam mengajarkan bila ingin memberikan hasil usaha baik berupa barang maupun pelayanan/jasa hendaknya memberikan yang unggul, jangan memberikan yang buruk kepada orang lain. Seperti dijelaskan dalam Al-Quran surat Al-Baqarah ayat 267 yang artinya:

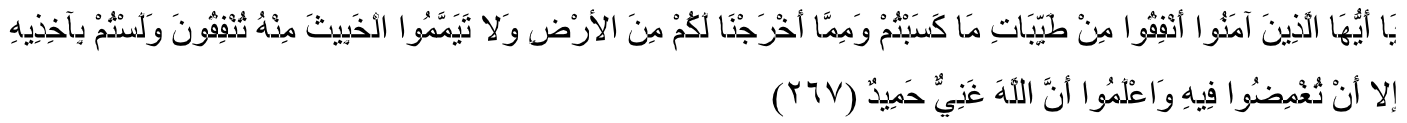

Artinya: "Hai orang-orang yang beriman, nafkahkanlah (dijalan Allah) sebagian dari hasil usahamu yang baik-baik dan sebagian dari apa yang kami keluarkan dari bumi untuk kamu dan janganlah kamu memilih yang buruk-buruk lalu kamu nafkahkan darinya padahal kamu sendiri tidak mau mengambilnya melainkan dengan memicingkan mata terhadapnya. Dan ketahuilah bahwa Allah Maha Kaya lagi Maha Terpuji” (Departemen Agama RI, 2004).

Hendaknya, seorang Muslim, sebelum melakukan sebuah perbuatan, sudah seharusnya berangkat dari sebuah pemahaman bahwa Islam sebenarnya telah memberikan aturan yang lengkap dan paripurna, termasuk dalam urusan duniawi, misalnya dalam bermuamalah, seperti dalam bertransaksi dengan para pelanggannya. Jadi, sebenarnya prinsip-prinsip marketing itu tidaklah berseberangan dengan nilai-nilai agama. Hal ini dikenal dengan istilah spiritual marketing.

Dalam bahasa syariah, spiritual marketing adalah tingkatan "pemasar langit", yang karena di dalam keseluruhan prosesnya tidak ada yang bertentangan dengan prinsipprinsip muamalah (bisnis syariah), ia mengandung nilai-nilai ibadah, yang menjadikannya berada pada puncak tertinggi dalam pemasaran atau muamalah. Hal ini merupakan refleksi dari ikrar seorang muslim ketika beribadah, "Qul inna sholati wanusuki wamahyaya wamamati lillahi robbil-alamin" (ya Allah, aku berikrar, sesungguhnya, ibadahku, hidupku, dan matiku hanya untuk Allah semata). Seorang muslim yang baik, dalam transaksi muamalahnya dalam hal ini pemasaran baik sebagai pemimpin perusahaan, pemilik, pemasar, pesaing, maupun sebagai pelanggan hendaklah menerapkan prinsipprinsip keadilan, kejujuran, transparansi, etika, dan moralitas menjadi nafas dalam setiap bentuk transaksi bisnisnya. Oleh karena itu, bagi seorang muslim, setiap hari jumat di masjid, ia selalu diingatkan khatib dalam penutupan khutbahnya, agar senantiasa berbuat adil ketika melakukan transaksi bisnis, senantiasa jujur, dan berbuat baik kepada orang lain (Gym dan Santoso, 2006).

Sebenarnya, spiritual marketing ini dapat dilaksanakan dengan optimal jika dalam segala aktivitas sehari-hari seorang muslim menempatkan Tuhan sebagai stakeholder utama. Inilah perbedaaan pokok antara pemasaran konvensional dan spiritual marketing. Seorang Muslim menempatkan Tuhan sebagai satu-satunya pemilik kepentingan (the ultimate stakeholder). Akuntabilitas dan responsibilitas diterjemahkan sebagai pertanggungjawaban di Padang Masyar (yaumul hisab) kelak, yang merupakan pengadilan abadi terhadap sepak-terjang manusia (termasuk para pelaku bisnis), baik yang tersurat 
maupun yang tersirat. Allah Swt. berfirman, "Apakah manusia mengira bahwa ia akan dibiarkan begitu saja (tanpa pertanggungjawaban)?”(QS Al-Qiyamah: 36).

Nabi Muhammad saw telah mengajarkan pada umatnya untuk selalu berbuat baik kepada orang lain. Inilah sebenarnya dasar dari pelayanan yang optimal (service execellent). Sabda Nabi, "Semoga Allah Swt memberikan rahmat-Nya kepada orangorang yang murah hati/sopan pada saat dia menjual, membeli, atau saat dia menuntut haknya". Allah Swt juga telah menginstruksikan untuk senantiasa berbuat baik kepada orang lain. Firman Allah Swt di antaranya terdapat dalam QS. Al-Hijr : 88,

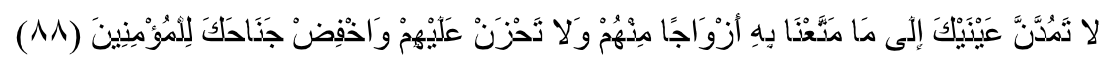

artinya: "Dan berendah dirilah kamu pada orang-orang yang beriman", juga dalam firman-Nya pada QS. Ali ’Imran : 159,

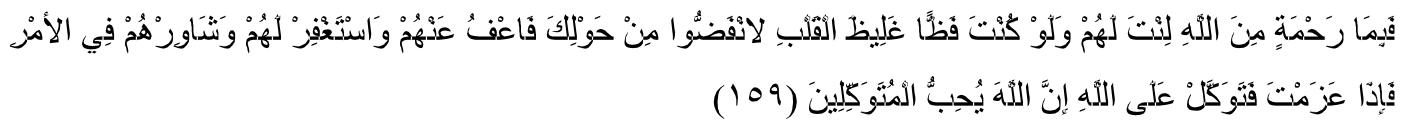

artinya: "Dan sekiranya kamu bersikap keras lagi berbuat kasar, tentulah mereka menjauhkan diri dari sekeliling kamu".

\section{Hipotesis}

Hipotesis dalam penelitian ini yang akan diuji adalah:

1. Terdapat perbedaan antara kepuasan pasien berpengaruh terhadap kepercayaan pasien di Rumah Sakit Islam dan Rumah Sakit RKZ Vincentius.

2. Terdapat perbedaan antara kepuasan pasien berpengaruh terhadap loyalitas pasien di Rumah Sakit Islam dan Rumah Sakit RKZ Vincentius.

3. Terdapat perbedaan antara kepercayaan pasien berpengaruh terhadap loyalitas pasien di Rumah Sakit Islam dan Rumah Sakit RKZ Vincentius.

\section{Model Analisis}

Berdasarkan hipotesis di atas, maka model analisis disajikan pada Gambar 1.

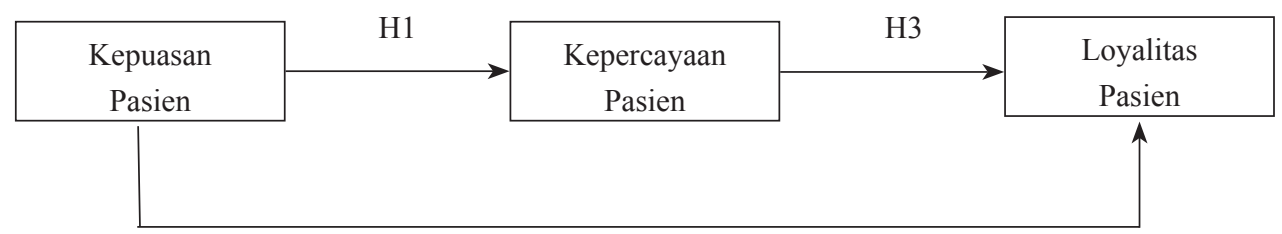

H3

Gambar 1. Model Analisis

\section{METODE PENELITIAN}

Pendekatan yang akan digunakan untuk penelitian ini adalah pendekatan penelitian kuantitatif. Populasi dalam penelitian ini adalah pasien yang melakukan pengobatan dan perawatan inap di Rumah Sakit Islam dan di Rumah Sakit RKZ Vincentius. Hal ini 
didasarkan pada teori dari Kelley (Hoffman, 2002) yang menyatakan bahwa penerapan pemasaran relasional menjadi bermanfaat bagi pelanggan dan perusahaan tersebut jika perusahaan tersebut memiliki customized yang tinggi dengan melibatkan karyawan (dokter dan perawat) untuk memberikan layanan tersebut.

Sampel dalam penelitian ini ditetapkan dengan ciri: pasien yang melakukan pengobatan dan perawatan inap di Rumah Sakit Islam dan di Rumah Sakit RKZ Vincentius selama lebih dari satu minggu dalam waktu Juni hingga Agustus 2013. Hal ini dimaksudkan agar pasien masih memiliki persepsi yang kuat mengenai apa yang dirasakan dan dialami selama masa pengobatan dan perawatan inap di rumah sakit tersebut, sehingga dapat meminimalisasi kemungkinan adanya bias karena pasien sudah lupa terhadap pelayanan dari rumah sakit tersebut. Jumlah sampel yang diteliti adalah 200 orang, hal ini didasarkan pada pendapat dari Aaker (1999) bahwa jenis ukuran sampel regional atau wilayah adalah 200 hingga 500 orang. Adapun, dari total sampel sebanyak 200 pasien, terbagi menjadi dua, yaitu 100 pasien di Rumah Sakit Islam dan 100 pasien di Rumah Sakit RKZ Vincentius.

Teknik pengambilan sampel berdasarkan non probability sampling, di mana peneliti tidak dapat memperoleh daftar seluruh anggota populasi (Danim, 1997). Cara penarikan sampel adalah purposive sampling, yaitu sengaja sampel yang dipilih adalah subjek yang tidak hanya sebagai pelaku langsung (pelanggan), akan tetapi juga memahami permasalahan penelitian yang menjadi fokus kerja peneliti (Danim, 1997).

Penelitian ini menggunakan teknik analisis jalur (path analysis), yaitu analisis statistik yang memungkinkan memberikan suatu tafsiran atau interpretasi bagi hubungan kausal dari sejumlah variabel dalam model. Penggunaan analisis jalur merupakan suatu metode yang digunakan untuk menelaah hubungan antar variabel pada model kausal yang telah dirumuskan peneliti atas dasar pertimbangan teoritis (Solimun, 2002).

\section{HASIL DAN PEMBAHASAN}

Setelah melalui uji validitas untuk msaing-masing indikator dalam variabel dan uji reliabilitas untuk msing-masing variabel, dan dihasilkan masing-masing indikator valid dan masing-masing variabel dinyatakan reliabel, maka dilakukan proses analisis data dengan menggunakan teknik analisis jalur.

\section{Hasil Pembuktian Hipotesis}

Pada penelitian ini parameter yang dijadikan acuan adalah membandingkan nilai signifikansi hitung dengan signifikansi standar 0,05. dan membandingkan CR hitung dengan CR standar 1,96.

1. Berdasarkan Tabel 1 dapat dijelaskan sebagai berikut:

Besarnya nilai CR hitung variabel kepuasan pasien pasien RSI terhadap kepercayaan pasien pasien RSI adalah 4,271. Tingkat signifikansi diperoleh nilai 0,026 , nilai ini lebih kecil dari 0,050. Oleh karena tingkat signifikansi ini kurang dari 0,050 maka kepuasan pasien berpengaruh terhadap kepercayaan pasien Rumah Sakit Islam.

2. Besarnya nilai CR hitung variabel kepercayaan pasien pasien RSI terhadap loyalitas pasien pasien RSI adalah 4,780. Tingkat signifikansi diperoleh nilai 0,035 , nilai ini lebih kecil dari 0,050. Oleh karena tingkat signifikansi ini kurang dari 0,050 maka kepercayaan pasien berpengaruh terhadap loyalitas pasien. Adanya pengaruh langsung dari kepuasan pasien terhadap kepercayaan pasien dan kepercayaan pasien 
terhadap loyalitas pasien menunjukkan bahwa kepuasan pasien berpengaruh secara tidak langsung terhadap loyalitas pasien tetapi harus melalui kepercayaan pasien di Rumah Sakit Islam. Hasil selengkapnya uji hipotesis dapat dilihat pada Tabel 1.

Tabel 1. Hasil Pengujian Hipotesis Pengaruh Langsung Pasien RSI

\begin{tabular}{|c|c|c|c|c|c|c|}
\hline \multicolumn{3}{|c|}{ Variabel } & \multirow{2}{*}{$\begin{array}{c}\text { CR } \\
\text { Hitung } \\
4,271\end{array}$} & \multirow{2}{*}{$\begin{array}{l}\text { Tingkat } \\
\text { Sig. } \\
0,026\end{array}$} & \multirow[t]{2}{*}{ Keterangan } & \multirow[t]{2}{*}{ Hipotesis } \\
\hline $\begin{array}{l}\text { Kepuasan pasien } \\
\text { (X) }\end{array}$ & $\Rightarrow$ & $\begin{array}{c}\text { Kepercayaan pasien } \\
\text { (Z) }\end{array}$ & & & & \\
\hline $\begin{array}{l}\text { Kepercayaan } \\
\text { pasien } \\
(\mathrm{Z})\end{array}$ & $\Rightarrow$ & $\begin{array}{l}\text { Loyalitas pasien } \\
\text { (Y) }\end{array}$ & 4,780 & 0,035 & \multirow[t]{2}{*}{$\begin{array}{l}\text { Ada pengaruh } \\
\text { (Signifikan) }\end{array}$} & \multirow[t]{2}{*}{ Diterima } \\
\hline $\begin{array}{l}\text { Kepuasan pasien } \\
\text { (X) }\end{array}$ & $\Rightarrow$ & $\begin{array}{l}\text { Loyalitas pasien } \\
\text { (Y) }\end{array}$ & 6,216 & 0,009 & & \\
\hline
\end{tabular}

Sumber : lampiran

Besarnya nilai CR hitung variabel kepuasan pasien pasien RSI terhadap loyalitas pasien pasien RSI adalah 6,216. Tingkat signifikansi diperoleh nilai 0,009, nilai ini lebih kecil dari 0,050. Oleh karena tingkat signifikansi ini lebih kecil dari 0,050. Maka variabel kepuasan pasien berpengaruh terhadap loyalitas pasien pasien Rumah Sakit Islam. Berdasarkan Tabel 2 dapat dijelaskan sebagai berikut:

1. Besarnya nilai CR hitung variabel kepuasan pasien pasien RKZ terhadap kepercayaan pasien pasien RKZ adalah 4,549. Tingkat signifikansi diperoleh nilai 0,006, nilai ini lebih kecil dari 0,050. Oleh karena tingkat signifikansi ini kurang dari 0,050 maka Kepuasan pasien berpengaruh terhadap Kepercayaan pasien Rumah Sakit RKZ di Surabaya.

2. Besarnya nilai $C R$ hitung variabel kepercayaan pasien pasien RKZ terhadap loyalitas pasien pasien RKZ adalah 3,577. Tingkat signifikansi diperoleh nilai 0,015 , nilai ini lebih kecil dari 0,050. Oleh karena tingkat signifikansi ini kurang dari 0,050 maka kepercayaan pasien berpengaruh terhadap loyalitas pasien. Adanya pengaruh langsung dari kepuasan pasien terhadap kepercayaan pasien dan kepercayaan pasien terhadap loyalitas pasien menunjukkan bahwa kepuasan pasien berpengaruh secara tidak langsung terhadap loyalitas pasien tetapi harus melalui kepercayaan pasien pada Rumah Sakit RKZ di Surabaya.

3. Besarnya nilai CR hitung variabel kepuasan pasien pasien RKZ terhadap loyalitas pasien pasien RKZ adalah 3,018. Tingkat signifikansi diperoleh nilai 0,019, nilai ini lebih kecil dari 0,050. Oleh karena tingkat signifikansi ini besar dari 0,050. Maka variabel kepuasan pasien berpengaruh terhadap loyalitas pasien Rumah Sakit RKZ di Surabaya. 
Tabel 2. Hasil Pengujian Hipotesis Pengaruh Langsung Pasien RKZ

\begin{tabular}{|c|c|c|c|c|c|c|}
\hline \multicolumn{3}{|c|}{ Variabel } & \multirow{2}{*}{$\begin{array}{c}\text { CR Hitung } \\
4,549\end{array}$} & \multirow{2}{*}{$\begin{array}{c}\begin{array}{c}\text { Tingkat } \\
\text { Sig. }\end{array} \\
0,006\end{array}$} & \multirow[t]{2}{*}{ Keterangan } & \multirow[t]{2}{*}{ Hipotesi } \\
\hline $\begin{array}{c}\text { Kepuasan pasien } \\
\text { (X) }\end{array}$ & $\Rightarrow$ & $\begin{array}{l}\text { Kepercayaan } \\
\text { pasien } \\
(\mathrm{Z})\end{array}$ & & & & \\
\hline $\begin{array}{c}\text { Kepercayaan pasien } \\
\text { (Z) }\end{array}$ & $\Rightarrow$ & $\begin{array}{l}\text { Loyalitas pasien } \\
\text { (Y) }\end{array}$ & 3,577 & 0,015 & $\begin{array}{c}\text { Ada pengaruh } \\
\text { (Signifikan) }\end{array}$ & Diterima \\
\hline $\begin{array}{c}\text { Kepuasan pasien } \\
\text { (X) }\end{array}$ & $\Rightarrow$ & $\begin{array}{c}\text { Loyalitas pasien } \\
\text { (Y) }\end{array}$ & 3,018 & 0,019 & & \\
\hline
\end{tabular}

Sumber : lampiran

\section{Kepuasan Pasien Berpengaruh terhadap Kepercayaan Pasien di Rumah Sakit Islam} dan Rumah Sakit RKZ Vincentius

Berdasarkan hasil analisis diperoleh nilai signifikansi kepuasan pasien berpengaruh terhadap kepercayaan pasien RSI adalah 0,026. Nilai ini masih di bawah 0,050, sehingga dinyatakan bahwa kepuasan pasien berpengaruh terhadap kepercayaan pasien RSI. Berdasarkan hasil analisis diperoleh nilai signifikansi kepuasan pasien berpengaruh terhadap kepercayaan pasien RKZ adalah 0,006. Nilai ini masih di bawah 0,050, sehingga dinyatakan bahwa kepuasan pasien berpengaruh terhadap kepercayaan pasien RKZ.

Hal ini sesuai dengan teori bahwa dalam perusahaan jasa, kepuasan merupakan hal yang penting untuk menciptakan kepercayaan di hati pelanggan tentang suatu produk yang ditawarkan. Bai et al (2008) membuktikan bahwa kualitas jasa mempengaruhi kepuasan pelanggan dan kepuasan pelanggan akan memberikan motivasi untuk berbelanja. Kepuasan pelanggan "memungkinkan" untuk mempengaruhi apakah pelanggan akan mencari kembali penyedia jasa dan membina hubungan jangka panjang (Rutledge \& Nascimento, 1996). Berry dan Parasuraman (1991) menemukan bahwa dalam hubungan jangka panjang antara perusahaan dengan pelanggannya dibutuhkan adanya faktor kepercayaan. Secara tersirat, uraian tersebut menunjukkan bahwa kepuasan yang dirasakan pelanggan akan berpengaruh terhadap kepercayaan pelanggan.

Pasien di RSI merasakan kepuasan atas pelayanan kesehatan baik saat rawat jalan maupun rawat inap, misalnya adanya dokter spesialis langganan yang penanganannya memberikan dampak baik bagi pasien (bisa menyembuhkan), berobat di rumah sakit ini bisa sembuh tanpa harus berobat ke rumah sakit yang lebih besar, dan sudah terbiasa berobat di Rumah Sakit Islam. Namun, RSI perlu memperhatikan keluhan pasien yang bisa berakibat kurangnya kepercayaan pasien terhadap RSI, yaitu masalah ketersediaan obat kurang dan pasien harus mencari di tempat lain.

Untuk pasien di RKZ, mereka kebanyakan merasakan kepuasan atas pelayanan kesehatan yang diberikan oleh dokter dan perawat. Mereka merasa pelayanan bagus dan sopan semua pegawainya walaupun harga di RKZ cukup mahal; puas dengan layanan, rapi, cepat tanggap dan juga ada ruangan khusus bagi keluarga; semua yang dibutuhkan selama pasien opname ada di RKZ; bangunannya asri, menjadikan betah dan nyaman di RKZ; puas karena dokternya berkualitas dan cepat tanggap tanpa harus mengurus admnistrasi dulu; pelayanan baik dan memuaskan; biaya yang dikeluarkan sebanding dengan pelayanannya (meski harganya cukup mahal), sehingga pasien kembali lagi kesini (sebulan yang lalu kena stroke, dan kembali lagi ke rumah sakit RKZ); pelayanannya 
bagus, dokter juga berkualitas, semua bagus meskipun harga mahal tetapi fasilitas lengkap dan worthed. Namun, RKZ juga perlu memperhatikan dengan serius dan perlu diberikan solusi atas keluhan pasien seperti kebersihan di dalam kamar agak kurang, karena masih banyak tempat yang berdebu, dan masih ada pembedaan perlakuan untuk pasien askes. Jika RKZ mengabaikan, dikhawatirkan akan dapat mengurangi kepuasan pasien.

\section{Kepuasan Pasien Berpengaruh terhadap Loyalitas Pasien di Rumah Sakit Islam dan Rumah Sakit RKZ Vincentius}

Berdasarkan hasil analisis diperoleh nilai signifikansi kepuasan pasien berpengaruh terhadap loyalitas pasien RSI adalah 0,009. Nilai ini masih di bawah 0,050, sehingga dinyatakan bahwa kepuasan pasien berpengaruh terhadap loyalitas pasien RSI. Berdasarkan hasil analisis diperoleh nilai signifikansi kepuasan pasien berpengaruh terhadap loyalitas pasien RKZ adalah 0,019. Nilai ini masih di bawah 0,050 , sehingga dinyatakan bahwa kepuasan pasien berpengaruh terhadap loyalitas pasien RKZ.

Hal ini sesuai dengan teori yang disampaikan oleh Aaker (1991); Oliver (1997) dalam penelitiannya menemukan adanya hubungan yang kuat antara kepuasan dengan loyalitas pelanggan. Aaker (1991) dan Oliver (1997) dalam penelitiannya menemukan adanya hubungan yang kuat antara kepuasan dengan loyalitas pelanggan. Namun, banyak penelitian akhir-akhir ini, menunjukkan bahwa kepuasan pelanggan dapat mempengaruhi loyalitas pelanggan dalam bentuk yang lebih kompleks (Bloemer \& Kasper, 1994); Oliver (1999); Reicheld (1993); dan Strauss \& Neuhaus (1997). Bloemer dan OdekerkenSchroder (2002) menjelaskan kompleksitas pengaruh kepuasan pelanggan terhadap loyalitas pelanggan dengan menyatakan bahwa kepuasan pelanggan berpengaruh terhadap loyalitas pelanggan, namun, kepercayaan dan komitmen merupakan dua konstrak yang berperan menjadi mediator diantara hubungan kepuasan dengan loyalitas tersebut.

Dalam tinjauan lapangan, hal ini dapat dibuktikan mengenai perasaan puas yang dirasakan oleh pasien, misalnya di RSI berkenaan dengan: fasilitas lengkap dan harga terjangkau dibanding rumah sakit lainnya, layanan yang diberikan sangat memuaskan dan cepat tanggap. Suasana nyaman, tempatnya bagus, rindang banyak tanaman, dan bersih. biaya tidak terlalu mahal dibandingkan dengan rumah sakit lainnya.

Namun, pihak RSI juga perlu memperhatikan keluhan pasien, diantaranya adalah: administrasi kurang puas, lelet, sehingga perlu ditingkatkan lagi, jam besuk kurang jelas, masjid kurang besar sehingga tidak ada tempat untuk sholat jumat, administrasinya ribet sedikit-sedikit pasien harus membayar karena tidak tercover menjadi satu sehingga tidak efisien, seringkali dokter memberikan resep dobel padahal resep lama masih belum dibelikan, dan rumah sakitnya agak sepi.

Di sisi yang lain, pasien RKZ memiliki kepuasan yang tergolong lebih tinggi daripada pasien RSI. Hal ini ditunjukkan dengan harapan pasien yang menjadi kenyataan di saat memilih berobat rawat jalan dan rawat inap di RKZ, misalnya: RKZ memiliki fasilitas lengkap dan pelayanan ramah, layanan lebih bagus dibandingkan dengan rumah sakit lainnya, harga standar dan didukung tenaga medis yang berkualitas, mempunyai persepsi bahwa pelayanan rumah sakit yang paling bagus, puas karena dokternya bagus dan penanganannya bagus/cepat (pasien datang langsung ditangani, dicarikan kamar dan dirawat sampai sembuh, ruangannya bersih, perawatnya handal merayu pasien anak kecil dari nangis sampai tidak nangis lagi, tidak ada perbedaan pasien kelas 1,2, 3. Pasien juga merasa seperti di rumah (disebabkan konsep rumah sakit yang hijau dan rindang), suster berkomitmen untuk tidak boleh menerima barang/uang dari pasien; dokter dan perawat 
memegang teguh komitmen melayani pasien, ramah, selalu memotivasi pasien untuk segera sembuh; sehingga pasien merasa sangat menyenangkan berobat di RKZ.

\section{Kepercayaan Pasien Berpengaruh terhadap Loyalitas Pasien di Rumah Sakit Islam dan Rumah Sakit RKZ Vincentius}

Berdasarkan hasil analisis diperoleh nilai signifikansi kepercayaan pasien berpengaruh terhadap loyalitas pasien RSI adalah 0,035. Nilai ini masih di bawah 0,050, sehingga dinyatakan bahwa kepercayaan pasien berpengaruh terhadap loyalitas pasien RKZ. Berdasarkan hasil analisis diperoleh nilai signifikansi kepercayaan pasien berpengaruh terhadap loyalitas pasien rumah sakit RKZ adalah 0,015. Nilai ini masih di bawah 0,050, sehingga dinyatakan bahwa kepercayaan pasien berpengaruh terhadap loyalitas pasien rumah sakit RKZ.

Hal ini sesuai dengan teori sebagai berikut: loyalitas pelanggan merupakan tujuan utama dari pemasaran relasional dan seringkali disamakan dengan konsep pemasaran relasional itu sendiri (Hennig-Thurau et al., 2002). Adanya kepercayaan, sebagai salah satu kunci utama dalam pemasaran relasional, yang dibangun oleh pelanggan, maka antara perusahaan dan pelanggan akan memiliki perasaan saling percaya, sehingga dapat berdampak positif bagi kedua belah pihak. Oleh karena itu, pihak penyedia jasa sudah seharusnya dapat dilihat oleh pelanggan sebagai pihak yang terpercaya, sehingga mampu membangun hubungan relasional yang berarti dan bernilai bagi pelanggan, apalagi dalam membangun hubungan jangka panjang (Hennig-Thurau et al., 2002); dan Morgan \& Hunt (1994).

Kepercayaan sering dianggap sangat penting untuk hubungan jangka panjang dan meningkatkan loyalitas pelanggan. Berry (1995) menjelaskan bahwa kepercayaan pelanggan merupakan sebuah peran penting dalam membangun hubungan jangka panjang dan meningkatkan loyalitas. Dengan kepercayaan sebagai pelopor, pelanggan menjadi loyal kepada perusahaan dan akan menunjukkan komitmennya pada perusahaan. Peran kepercayaan sebagai pengaruh meningkatnya loyalitas didukung oleh temuan empiris dari Eriksson Vaghult (2000) dan Sirdesmukh et al. (2002) yang menjelaskan bahwa kepercayaan secara langsung terkait dengan loyalitas. Dalam penelitian tersebut, di samping pengaruh positif kepercayaan terhadap loyalitas, menunjukkan bahwa ketika kepercayaan pelanggan meningkat, secara otomatis loyalitas pelanggan tersebut ikut meningkat.

Di samping itu, nilai koefisien determinasi dibandingkan antara pasien RSI dengan pasien RKZ, maka pengaruh kepuasan pasien pasien RSI dan kepercayaan pasien pasien RSI terhadap loyalitas pasien pasien RSI adalah 45,9\% atau lebih besar daripada pasien RKZ. Hal ini disebabkan kepuasan pasien RSI lebih besar daripada kepuasan pasien RKZ karena hubungan antara pasien dengan pihak RSI lebih didasarkan pada ikatan religius. Hal ini nampak dalam Nilai Dasar Rumah Sakit Islam disingkat dengan SYIFA (Şiddīq, Yaqin, Iman, Faţānah, dan Amānah), yang memiliki makna sebagai berikut:

$\mathrm{S}$ : Şiddīq, Rumah Sakit Islam memiliki sumber daya manusia yang jujur dengan memiliki integritas dan kemandirian

Y : Yaqin, Rumah Sakit Islam memiliki keyakinan terhadap potensi diri dan kesembuhan pasien adalah berkat rahmat Allah Subhānahu wa Ta'alā.

I : Iman, setiap tindakan yang dilakukan pegawai Rumah Sakit Islam dilandasi keimanan kepada Allah Allah Subhānahu wa Ta 'alā, disertai ikhlas dalam pelayanan dan bersifat fleksibel. 
F : Faţānah, setiap pegawai Rumah Sakit Islam senantiasa cerdas dalam menangkap peluang dan selalu meningkatkan pengetahuan dan sikap.

A : Amānah, Rumah Sakit Islam dapat diandalkan dan transparan dalam menjalankan tugas yang menjadi tanggung jawabnya.

Pasien RSI menganggap bahwa dengan berobat ke RSI, telah sesuai dengan syariat Islam. Dokter spesialis lengkap dan terpercaya serta suka memberikan wejangan religius, dan perawatnya lebih perhatian dan melayani sepenuh hati dan ramah dibanding rumah sakit lainnya yang acuh tak acuh. Hal ini tentu sejalan dengan nilai Islam, bahwa sebenarnya, jauh sebelum para ahli pemasaran konvensional berbicara, ribuan tahun lampau, maka Allah Swt telah memberikan tuntunan kepada umat-Nya, agar ketika memproduksi barang atau memberikan layanan kepada saudaranya (pelanggannya), maka sudah seharusnya memberikan yang baik. Ketika seorang pemasar menyebut nama Tuhan-nya Yang Maha Pengasih lagi Maha Penyanyang ketika ia memulai sesuatu, berarti ia tidak mengharapkan apapun, kecuali keberkahan dan keridhaan dari Tuhan-nya (spiritual goal). Kalaupun ada tujuan lainnya-emotional goal atau rational goal- maka pemasar tidak akan menempatkannya lebih tinggi daripada spiritual goal. Hal inilah yang menjadi motivasi mendasar dari seorang Muslim dalam melakukan apapun, termasuk didalamnya adalah melakukan usaha perdagangan dan pemasaran yang berbeda dengan motivasi seorang yang melepaskan ajaran Islam dari kehidupannya, dimana mereka hanya berorientasi pada materi/laba (Gym dan Santoso, 2006).

Selain itu, yang menjadikan pasien memiliki kepercayaan terhadap pelayanan rawat jalan dan rawat inap di RSI adalah sebagai berikut: RSI memberikan fasilitas yang lengkap tanpa harus mengeluarkan uang lebih banyak, keamanan cukup tetapi masalah harga kurang mendukung, percaya karena pasien sudah sering berobat ke rumah sakit ini, RSI menjadi rumah sakit rujukan bagi keluarga besar pasien, RSI sudah memiliki nama yang kredibel.

Sedangkan di RKZ, pasien percaya terhadap pelayanan rawat jalan dan rawat inap di RKZ disebabkan RKZ memiliki peralatan medis yang canggih sehingga merasa lebih baik, kinerja pelayanan kesehatan yang cepat dan tanggap terhadap kebutuhan pasien, sistem manajemennya terorganisir, dokter dan perawat disiplin, tidak menjadikan pusing pasien karena tidak banyak orang berlalu lalang di sini, dokter dan perawatnya berkualitas, memiliki integritas tinggi, keamanan yang baik dan didukung obat yang lengkap, jam jenguk sesuai, makanan, tempat yang bersih, didukung obat yang lengkap, RKZ sangat tertib dan menjaga kebersihan jadi pasien tidak ragu lagi untuk datang, selain itu juga pasien merasa percaya karena beberapa temannya berobat juga ke RKZ, dan RKZ lebih kredibel dalam merawat pasien. Namun, pasien masih ada yang mengeluhkan mengenai jam jenguk yang terbatas dan harus bergantian.

\section{SIMPULAN DAN SARAN}

\section{Simpulan}

Kesimpulan yang diperoleh dari penelitian ini sebagai berikut:

1. Kepuasan pasien berpengaruh terhadap kepercayaan pasien pasien RSI dan RKZ.

2. Kepuasan pasien berpengaruh terhadap loyalitas pasien pasien RSI dan RKZ.

3. Kepercayaan pasien berpengaruh terhadap loyalitas pasien pasien RSI dan RKZ. 


\section{Saran}

Saran yang diperlukan agar penelitian ini berjalan dengan baik adalah:

1. Bagi pihak manajemen Rumah Sakit Islam, sebaiknya perlu memperhatikan keluhan pasien, diantaranya adalah:administrasikurang puas, lelet, sehingga perlu ditingkatkan lagi, jam besuk kurang jelas, masjid kurang besar sehingga tidak ada tempat untuk sholat jumat, administrasinya ribet sedikit-sedikit pasien harus membayar karena tidak tercover menjadi satu sehingga tidak efisien, seringkali dokter memberikan resep dobel padahal resep lama masih belum dibelikan, dan rumah sakitnya agak sepi dari pasien, sehingga perlu meningkatkan usaha promosi agar pasien bersedia berobat rawat inap ke RSI.

2. Bagi pihak manajemen RKZ, sebaiknya memberikan kelonggaran jam jenguk kepada keluarga dan rekan pasien dan tidak harus bergantian, karena pasien di Indonesia masih merasakan perhatian dari keluarga dan orang dekatnya mampu memberikan sugesti kesembuhan, namun juga diharapkan kesadaran dari penjenguk agar tidak mengganggu istirahat pasien.

3. Bagi penelitian selanjutnya, perlu dilakukan penelitian dengan memasukkan variabel tingkat pengetahuan agama dan gender sebagai variabel moderator.

\section{REFERENSI}

Aaker, David A. 1991. Managing Brand Equity: Capitalizing on The Value of A Brand Name. Simon and Schuster (Asia) Pte. Ltd. Terjemahan. Aris Ananda. 1997. Cetakan Pertama. Jakarta. Penerbit Mitra Utama.

Abratt, Russel and Joy Russel. 1999. Relationship Marketing in Private Banking in South Africa. International Journal of Bank Marketing. Vol. 17. No. 1. pp. 5-19.

Beatty, S.E. 1996. Customer Sales Associate Retail Relationships. Journal of Retailing. Vol. 72. No. 3. pp. 223-247.

Bloemer, Josee and Gaby Odekerken-Schroder. 2002. Store Satisfaction and Store Loyalty Explained by Customer - and Store - Related Factors. Journal of Consumer Satisfaction, Dissatisfaction and Complaining Behavior. 15. ABI/INFORM Research. pp 68.

Chaplin, Ed and John Terninko. 2000. Customer-Driven Healthcare: QFD for Process Improvement and Cost Reduction. ASQ Quality Press. Milwaukee, Wisconsin.

Depag RI, Al Qur'an dan Terjemahannya Al-Jumanatul 'Ali, 2004, J-ART, Bandung.

Emnew, C. T., and Morris R. Binks. 1996. The Impact of Service Quality and Service Characteristics on Customer Retention: Small Business and Their Banks in UK". British Journal of Management. 17. September. pp. 219-230.

Firdaus, Muhammad, Muhammad Aziz Hakim, Sofiniyah Ghifron, dan Mukhtar Alshodiq. 2005. Dasar dan Strategi Pemasaran Syariah. Penerbit Renaisans. Jakarta. 
Garbarino, Ellen and Mark S. Johnson. 1999. The Different Roles of Satisfaction, Trust, and Commitment in Customer Relationships. Journal of Marketing. Vol. 63. pp. $70-87$.

Gronroos, Christian. 1997. Keynote paper: From Marketing Mix to Relationship Marketing - Towards a Paradigm Shift in Marketing. Management Decisions. Vol. 35. No. 4.

. 1994. From Marketing Mix to Relationship Marketing - Towards a Paradigm Shift in Marketing. Management Decisions. Vol. 32. No. 2. pp. 4-20.

Gummesson, Evert. 2000. Total Relationship Marketing. Second Edition. ButterworthHeinemann. Elsevier Science. Woburn MA.

Gym AA dan Ippho Santoso. 2006. Qalbu Marketing: 7 Kunci Menuju Kemenangan. Kelompok Mizan. Jakarta.

Hennig-Thurau, Thorsten and Alexander Klee. 1997. The Impact of Customer Satisfaction and Relationship Quality on Customer Retention. Psychology and Marketing. December.

Hoffman, Nicole Ponder. 2002. The Theory of Customer Intimacy: Towards An Understanding of Relationship Marketing In A Professional Sevice Setting. UMI Microform 3027353. Bell and Howell Information and Learning Company.

Kartajaya, Hermawan dan Muhammad Syakir Sula. 2006. Syariah Marketing. Penerbit Mizan dan MarkPlus\&Co. Jakarta. Cetakan Ketiga.

Keegan, Warren J. Sandra E. Moriarty, and Thomas R. Duncan. 1995. Marketing. Second Edition. Englewood Cliffs, New Jersey. Prentice Hall, Inc.

Lovelock, Christopher. 1992. Managing Services: Marketing, Operations, and Human Resources. Seventh Edition. New Jersey. Prentice Hall.

Malhotra, Naresh K. 1999. Marketing Research: An Applied Research. Third Edition. International Edition. New Jersey. Prentice Hall International, Inc.

Moorman, C., Rohit Deshpande, and Gerald Zaltman. 1993. Factors Affecting Trust in Market Research Relationships. Journal of Marketing. January. pp. 81-101.

Morgan, Robert M. and Shelby D. Hunt. 1994. The Commitment-Trust Theory of Relationship Marketing. Journal of Marketing. Vol. 58. pp. 20-38.

Oliver, Richard L. 1997. Satisfaction: A Behavioral Perspective on The Consumer. International Edition. Singapore. The McGraw-Hill Companies, Inc.

Peppers, Don and Martha Rogers. 2004. Managing Customer Relationships: A Strategic Framework. John Wiley and Sons, Inc.

Reicheld, Frederick F. 1993. Loyalty Rules!: How Today's Leaders Build Lasting Relationships. Harvard Business School Press. Bain and Company, Inc. United States of America. 
Rutledge, Robert and Patricia Nascimento. Satisfaction with HMO's. Journal of Health Care Marketing. Vol. 16. No. 1. pp. 22-27. 1996.

Schiffman, Leon G. and Leslie Lazar Kanuk. 2004. Consumer Behavior. New Jersey. Prentice Hall International, Inc.

Shemwell, Donald J., Ugur Yavas, and Zeyneb Bilgin. 1998. Customer-Service Provider Relationships: An Empirical Test of A Model of Service Quality, Satisfaction, and Relationship-Orientef Outcomes. International Journal of Service Industry Management. Vol. 9. No. 2. pp. 155-168.

Sheth, Jagdish N. and Atul Parvatiyar. 1995. Relationship Marketing in Consumer Markets: Antecedents and Consequencies. Journal of The Academy of Marketing Science. Vol. 23. No. 4. pp. 255-271.

Silverhart, Todd A. 2004. A Question of Trust. LIMRA's Marketfacts Quarterly. Winter. Vol. 23. No. 1.

Solimun. 2002. Structural Equation Modelling Lisrel dan Amos. Fakultas MIPA Universitas Brawijaya. Malang.

Ullrich, D. 1994. Tie The Corporate Knot: Gaining Complete Customer Commitment. Sloan Management Review. Vol. 30. Summer. pp. 19-27.

Webster Jr., Frederick E. 1994. Market Driven Management: Using The Marketing Concept to Create A Customer Oriented Company. New York. John Wiley and Sons, Inc. 
